\title{
Does treatment with bisphosphonates protect against fractures in real life? The HUNT study, Norway
}

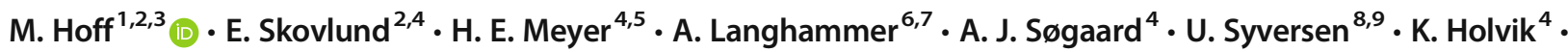 \\ B. Abrahamsen ${ }^{10,11}$ B. Schei ${ }^{2,12}$
}

Received: 4 September 2020 / Accepted: 11 January 2021 / Published online: 21 January 2021

(C) The Author(s) 2021

\begin{abstract}
Summary Bisphosphonates reduce fractures in randomized controlled trials (RCT); however, there is less information from real life. In our population including 14,990 women and 13,239 men, use of bisphosphonates reduced risk of fractures in hip and forearm in women. The magnitude of the effect was comparable to results from RCT.

Introduction The objective was to examine if treatment with bisphosphonates (BPs) was associated with reduced risk of fractures in the hip and forearm in women and men in the general population.

Methods In a cohort study based on data from the third wave of the population-based HUNT Study (HUNT3), the fracture registry in Nord-Trøndelag, and the Norwegian Prescription Database, 14,990 women and 13,239 men 50-85 years were followed from the date of participating in HUNT3 (2006-2008) until the date of first fracture in the hip or forearm, death, or end of study (31 December 2012). Hazard ratios with $95 \%$ confidence intervals for hip and forearm fracture according to use of BPs were estimated using Cox proportional hazards models with time-dependent exposure. Adjustment for individual FRAX® fracture risk assessment scores was included.

Results BPs, predominantly alendronate, were used by $9.4 \%$ of the women and $1.5 \%$ of the men. During a median of 5.2 years of follow-up, 265 women and 133 men had a hip fracture, and 662 women and 127 men had a forearm fracture. Compared with nonusers of BPs, the hazard ratios with $95 \%$ confidence interval for a fracture among users of BPs adjusted for age and FRAX ${ }^{\circ}$ were $0.67(0.52-0.86)$ for women and $1.13(0.50-2.57)$ for men. Among users of glucocorticoids, the corresponding figures were 0.35 (0.19-0.66) and $1.16(0.33-4.09)$, respectively.

Conclusions Use of BPs was associated with reduced risk of fractures in hip and forearm in women, and the magnitude of effect is comparable to results from RCTs.
\end{abstract}

Keywords Anti-osteoporotic drugs $\cdot$ Cohort study $\cdot$ Fractures $\cdot$ General population studies $\cdot$ HUNT $\cdot$ Osteoporosis

M. Hoff

mari.hoff@ntnu.no

1 Department of Neuromedicine and Movement Science, Norwegian University of Science and Technology, NTNU, Trondheim, Norway

2 Department of Public Health and Nursing, Norwegian University of Science and Technology, NTNU, Trondheim, Norway

3 Department of Rheumatology, St. Olavs hospital, Trondheim University Hospital, Trondheim, Norway

4 Norwegian Institute of Public Health, Oslo, Norway

5 Department of Community Medicine and Global Health, University of Oslo, Oslo, Norway
6 HUNT Research Centre, Department of Public Health and Nursing, Norwegian University of Science and Technology, NTNU, Trondheim, Norway

7 Levanger Hospital, Nord-Trøndelag Hospital Trust, Levanger, Norway

8 Department of Endocrinology, St. Olavs hospital, Trondheim University Hospital, Trondheim, Norway

9 Department of Clinical and Molecular Medicine, Norwegian University of Science and Technology, NTNU, Trondheim, Norway

10 Department of Medicine, Holbæk Hospital, Holbæk, Denmark

11 Odense Patient Data Explorative Network, Institute of Clinical Research, University of Southern Denmark, Odense, Denmark

12 Department of Gynecology, St. Olavs hospital, Trondheim University Hospital, Trondheim, Norway 


\section{Introduction}

Osteoporosis is a skeletal disease characterized by low-bone mineral density (BMD) and microarchitectural deterioration of bone tissue, leading to bone fragility and increased fracture risk [1]. Over the last decades, several anti-osteoporotic drugs (AODs) have emerged, including inhibitors of bone resorption such as bisphosphonates (BPs), raloxifene, and denosumab, as well as teriparatide, romosozumab, and abaloparatide which stimulate bone formation $[2,3]$.

Treatment with AODs has in randomized clinical trials (RCTs) been found to reduce the relative fracture risk for vertebral and non-vertebral fractures by $40-80 \%$ and 20 $60 \%$, respectively [4-6]. Oral BPs, preferentially alendronate, are the most widely used worldwide because they are effective and inexpensive [3]. Most RCTs have included women with postmenopausal osteoporosis, excluding cases with secondary osteoporosis and those with several diagnoses. In contrast, patients treated in clinical practice are more heterogenous and include frail individuals with comorbidities $[7,8]$.

Reyes et al. observed that half of the patients who received alendronate treatment had secondary or severe osteoporosis [9]. A few RCTs have addressed secondary osteoporosis, preferentially glucocorticoid (GC)-induced osteoporosis (GIOP). A meta-analysis including 10 studies and 1002 patients with GIOP showed that alendronate increased BMD of the lumbar spine and femoral neck without a corresponding effect on fracture risk [10]. In contrast, a Cochrane review concluded that BPs reduced vertebral fractures and prevented bone loss both in the lumbar spine and femoral neck. An effect on nonvertebral fractures was not found; however, according to the authors the effect of non-vertebral fracture was of lowcertainty evidence [11].

In real life, adherence to oral BPs is generally low compared to that in RCTs $[7,8]$, and premature cessation of treatment is particularly common in men [12]. Discontinuation of BPs may be due to polypharmacy or side effects [3]. The adherence is also dependent on the route of administration of the drug. These factors may contribute to a reduced external validity of results from RCT.

There is little information regarding the effect of BPs in the general population. Danish and Swedish registry studies have reported 30\% risk reduction in hip fractures in women aged 50-94 years [7, 13, 14]. Similarly, a large population-based study from the USA showed a $21 \%$ reduced risk of any clinical fracture in users of BPs, when comparing 1-year fracture incidence before and after initiating treatment [8].

Although the incidence of osteoporotic fractures in Norway is among the highest in the world, the prescription of BPs has been relatively low compared to some other European countries; a little less than $5 \%$ among all women $>40$ years [15-18]. In the HUNT study, prescription of AODs (whereof BPs contributed to 98\%) was low even among individuals with high fracture risk assessed by the Fracture Risk Assessment Tool, FRAX® (www.FRAX.com). FRAX® predicts the 10-year absolute risk of hip fracture as well as a major osteoporotic fracture. Only $25 \%$ of the women and $17 \%$ of the men with $>20 \%$ risk of a major osteoporotic fracture were treated with AODs [16]. Moreover, merely $11 \%$ of the women and $3 \%$ of the men used AODs the first year after a forearm fracture [15].

The objective of this study was to examine if use of BPs was associated with reduced risk of fractures in the hip and forearm in women and men aged 50-85 years in a Norwegian population.

\section{Methods}

\section{Data sources}

Participants from the third survey of the HUNT Study (HUNT3) comprised the study population. Their data were linked to the fracture registry of Nord-Trøndelag and the Norwegian Prescription Database (NorPD) via the national personal identification number.

\section{The Trøndelag Health Study (HUNT study)}

HUNT3 was performed from 2006 to 2008 in the county of NordTrøndelag, located in mid-Norway. The geographic, demographic, and occupational structure is considered fairly representative of the country as a whole [19]. All individuals aged 20 years and older residing in the county were invited to participate.

In the current study, we included the age group 5085 years. Of the 43,760 invited, 28,692 (65.6\%) responded, completed a comprehensive questionnaire, and underwent a short clinical examination at the screening station. Of these, 231 were excluded due to lack of data on height $(N=213)$ or weight $(N=220)$ and 26 used other AODs than BPs, leaving 14,990 women and 13,239 men (Fig. 1).

\section{The fracture registry of Nord-Trøndelag}

The registry provides validated information on forearm and hip fracture in subjects older than 16 years, treated, or followed up from 15 August 1995 to 31 December 2012 at the two hospitals located in Nord-Trøndelag County. Data were retrieved through the electronic discharge registers, namely The Patient Administrative System (PAS) based on diagnoses coded according to the International Classification of Diseases (ICD), as well as surgical procedures coded according to the NOMESCO Classification of Surgical Procedures (NCSP). A fracture was defined when (1) the ICD code was accompanied by a medical record confirmation of hip fracture or (2) a fracture was diagnosed by $\mathrm{X}$-ray. 


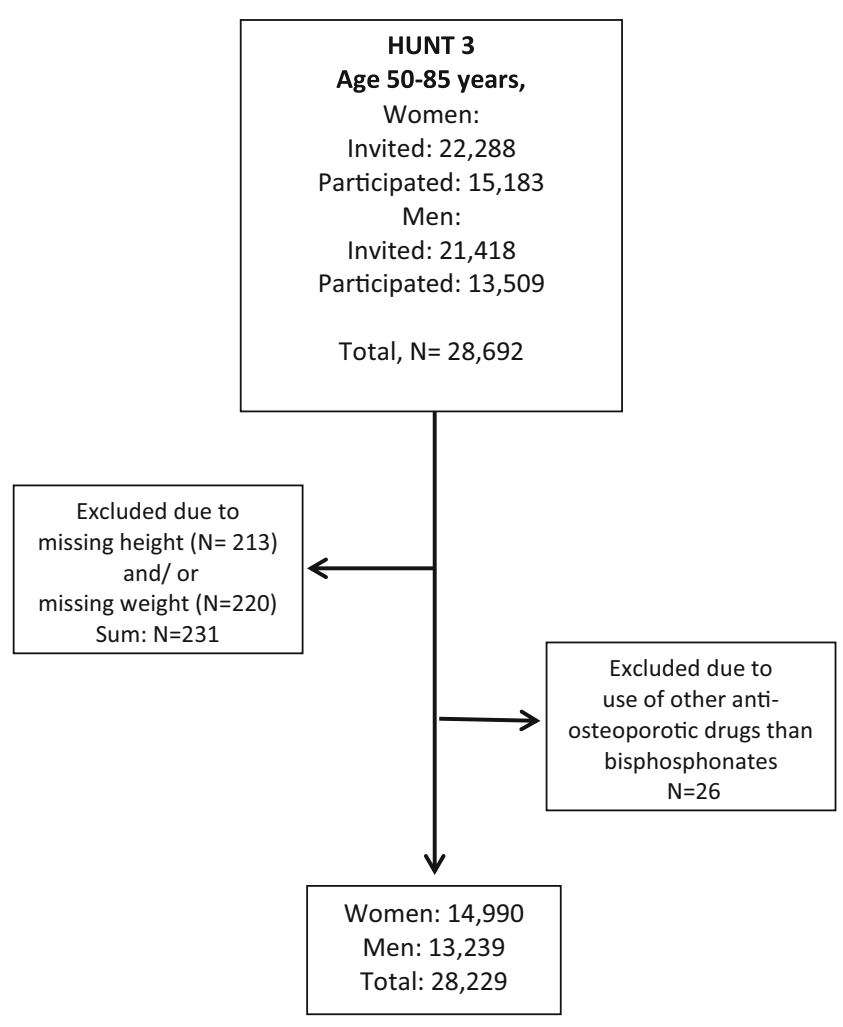

Fig. 1 Flowchart of the included subjects

Fractures due to metastatic disease were excluded. Details about the classification and validity of this fracture information have been published previously [15, 20, 21].

\section{Norwegian Prescription Database (NorPD)}

Data on prescriptions of BPs and oral GCs were collected from the NorPD established 01 January 2004. NorPD contains information on all prescribed drugs that are dispensed at all pharmacies in Norway to individual patients in ambulatory care. Drugs prescribed to patients in hospital or other institutions, are not registered in NorPD [22]. Month of death was retrieved form the NorPD. Information regarding other types of AODs, including denosumab (M05BX04), raloxifene (G03XC01), and teriparatide (H05AA02), were also collected from the NorPD as use of these was an exclusion criterion from the study.

\section{Exposure: bisphosphonates}

For each individual, exposure to BPs, based on filled prescriptions with Anatomical Therapeutic Chemical (ATC) code M05BA with all subgroups, was registered from 1 year before participation in HUNT3 and until either fracture, death, or end of study (31 December 2012).

Time-dependent exposure of BPs was applied to estimate the association between such use and risk of fractures. Individuals who filled at least two prescriptions for bisphosphonates within a 6-month period at any time during follow-up were defined as exposed from the date of filling the first prescription until 6 months after estimated end of drug supply. An exception from this was use of zoledronic acid where the inclusion criterion was one infusion per year.

\section{Outcome: fracture}

Data on first forearm or hip fracture after the HUNT3 examination until study end were obtained from the fracture registry of Nord-Trøndelag. The ICD 10 codes included to identify hip fractures were S72.0-2 and 9, and for forearm fractures S52.0-S52.9.

\section{Covariates}

Fracture risk was calculated by use of the FRAX® (www.shef. ac.uk/FRAX) (for Norway) [23]. Individual FRAX scores in terms of predicted 10-year risk of hip fracture $\left(\mathrm{FRAX}_{\mathrm{HIP}}\right)$ and major osteoporotic fracture $\left(\mathrm{FRAX}_{\mathrm{MOF}}\right)$ without $\mathrm{BMD}$ were calculated based on information from the HUNT study and the NorPD; details are previously described [24].

The following variables were included in the FRAX calculation: gender, age, body mass index (BMI), self-reported previous fracture, parental hip fracture, current smoking, use of alcohol (units per week), use of oral GCs, rheumatoid arthritis (RA), and other causes of secondary osteoporosis, including diabetes type 1, premature menopause, and hyperthyroidism. We did not have any information regarding malabsorption, chronic liver disease, or osteogenesis imperfecta. As the fracture register was established in 1995 and only contains fractures in the hip and wrist, self-reported fractures at the hip, spine, or wrist after the age of 40 years in HUNT3 were included.

There were no self-reported data on use of oral GCs in HUNT3, so this information was retrieved from the NorPD (ATC code H02A and H02B). In line with the guidelines of FRAX, use of at least $5 \mathrm{mg}$ GCs for more than 3 months prior to the inclusion in HUNT3 or current use were included in the FRAX calculation [24] (www.FRAX.com).

All other information regarding FRAX was collected from HUNT3 [24].

\section{Statistics}

Descriptive data are given as means with standard deviations (SD) for continuous data and numbers and percentages for categorical data, and 95\% confidence intervals (CIs) for counts were calculated by the continuity-corrected score interval method [25].

Cox proportional hazards model with time-dependent exposure to BPs was used to assess the association between BPs and fracture rates. Here, for each time increment (months) an individual would be classified as unexposed or exposed according to the description in the "Exposure: bisphosphonates" section. Thus, an individual may contribute with unexposed 
time during the first part of follow-up, switch to exposed when fulfilling the exposure criteria, and possibly become unexposed at a later point in time. The study population was followed from the date of participating in HUNT3 (the index date) until date of first fracture, death, or end of study (31 December 2012), whichever came first.

We present three models: the first adjusted for age, the second adjusted for FRAX $\mathrm{XOF}_{\mathrm{MOF}}$ without $\mathrm{BMD}$, and the third adjusted for both age and FRAX $\mathrm{X}_{\mathrm{MOF}}$ without BMD for analyses of the composite endpoint of hip- and forearm fracture. FRAX $_{\text {HIP }}$ without BMD was used in the models with hip fracture as outcome.

The proportional hazards assumptions were checked by visual inspection of $\log$ minus $\log$ plots.

For descriptive purposes medication possession ratio (MPR) was calculated as a measure of compliance. MPR is defined as the proportion of a time period where medication supply is available and was calculated as the total amount defined daily dose (DDD) prescribed/(last fill date - first fill date + DDD of the last prescription). Adherence was defined as MPR $\geq 80 \%[26,27]$. The estimate for MPR is only descriptive and not included in our statistical models.

In our main analyses, we assessed the composite endpoint of first hip or forearm fracture in women and men separately. In addition, we also assessed hip and forearm fractures separately.

\section{Sensitivity analyses}

The impact of BPs was assessed in the following subgroups among women: secondary osteoporosis, those using GCs, and those with high risk for fractures classified as having a FRAX $_{\text {MOF }}$ score $\geq 20 \%$.

As the effect of BPs is dependent on the duration of use [3], we also applied models with different assumptions on duration of exposure to BPs after the last filled prescription. In addition to our primary analysis, assuming that the effect on bone would last for 6 months after termination of drug supply, we also performed separate analyses replacing this assumption with 3 and 9 months, as well as censoring 6 months after stopping BP treatment.

In additional sensitivity analyses, we estimated propensity scores for BP exposure by logistic regression including age, BMI, previous fractures, osteoporosis among parents, smoking, daily milk intake, alcohol consumption, exposure to glucocorticoids, rheumatoid arthritis, premature menopause, hyperthyroidism, and diabetes type 1 as covariates. We compared the distribution of propensity scores between users and never users of PPIs and performed a stratified analysis using 6 strata as well as separate analyses in each stratum (women) to assess whether the association seemed to differ between strata.
All analyses were done using STATA 14.1 (StataCorp. 2015. Stata Statistical Software: Release 14. College Station, TX: StataCorp LP).

\section{Ethics}

Participants in HUNT3 gave written informed consent for use of their data in research including linkage to named registries, such as NorPD. The study was approved by the Regional Committee for Medical and Health Research Ethics in Central Norway (2012/1906/REK). Linkage of databases was approved by the Norwegian Data Protection Authority.

\section{Results}

\section{Use of bisphosphonates}

The study includes 14,990 women and 13,239 men (Fig. 1). Alendronate was by far the most prescribed BPs, used by $98 \%$ of the women and $99 \%$ of the men. Only 26 individuals were excluded in the analyses due to use of other AODs (Fig. 1 and Supplementary Table 1).

A total of 1402 women (9.4\%) and 201 men (1.5\%) met the criteria of filling at least two prescriptions of peroral BPs during a 6-month period or infusion of zoledronic acid once a year and were included in the analysis. Four women and one man had been treated with zoledronic acid as the only BPs, while 57 women and 7 men used zoledronic acid after side effects from peroral BPs (Supplementary Table 1). We classified 251 women and 72 men who filled only one prescription for peroral BPs as non-users.

Those treated with BPs were substantially older than those who were not, with a mean age at baseline of 70.2 and 68.6 years for women and men, respectively. Among those treated with BPs, women reported more previous fractures (44.5\% vs. $26.9 \%)$ and osteoporosis among parents than men $(29.8 \%$ vs. $16.9 \%)$. A larger proportion of men than women using BPs had secondary osteoporosis $(63.7 \%$ vs. $50.4 \%$ ), and of these, 120 men and 441 women were treated with GCs (59.7\% vs. $31.5 \%)$ (Table 1$)$.

The mean duration of use of BPs was 52.2 months (SD 27.8) among women and 42.9 months (SD 26.9) for men. Regarding adherence among the included participants with at least two filled prescriptions, $79.8 \%$ of the women and $77.1 \%$ of the men had an MPR $\geq 80$ during follow-up.

\section{Fracture risk according to use of bisphosphonates}

During a median of 5.2 years follow-up, 265 women and 133 men had a first hip fracture, and 662 women and 127 men had a first forearm fracture. Among women with fractures, 94 were treated with BPs and 828 were not. The respective 
Table 1 Baseline values stratified for use of bisphosphonates ${ }^{1}$ in the follow-up period

\begin{tabular}{|c|c|c|c|c|}
\hline & \multicolumn{2}{|c|}{ Women, $N=14,990$} & \multicolumn{2}{|l|}{ Men, $N=13,239$} \\
\hline & $\begin{array}{l}\text { Exposed to } \\
\text { bisphosphonates } \\
N=1402\end{array}$ & $\begin{array}{l}\text { Not exposed to } \\
\text { bisphosphonates } \\
N=13,588\end{array}$ & $\begin{array}{l}\text { Exposed to } \\
\text { bisphosphonates } \\
N=201\end{array}$ & $\begin{array}{l}\text { Not exposed to } \\
\text { bisphosphonates } \\
N=13,038\end{array}$ \\
\hline Age, years mean (SD) & $70.2(8.7)$ & $63.2(8.9)$ & $68.6(9.0)$ & $63.6(898)$ \\
\hline $\mathrm{BMI}, \mathrm{mg} / \mathrm{kg}^{2}$ mean $(\mathrm{SD})$ & $26.3(4.5)$ & $27.7(4.7)$ & $26.7(4.0)$ & $27.7(3.7)$ \\
\hline $\begin{array}{l}\text { FRAX® calculated 10-years risk of } \\
\text { major osteoporotic fracture, mean (SD) }\end{array}$ & $26.3(15.6)$ & $12.3(9.5)$ & $12.2(8.9)$ & $6.3(3.7)$ \\
\hline Previous fractures, $N(\%)^{\mathrm{b}, \mathrm{c}}$ & $624(44.5)$ & $1980(14.6)$ & $54(26.9)$ & $1276(9.8)$ \\
\hline Osteoporosis among parents, $N(\%)^{\mathrm{b}}$ & $418(29.8)$ & $1513(11.1)$ & $34(16.9)$ & $795(6.1)$ \\
\hline Current smoker, $N(\%)^{\mathrm{b}}$ & $307(21.9)$ & $3204(23.6)$ & $40(19.9)$ & $2785(21.4)$ \\
\hline More than 2 glass milk/day, $N(\%)^{\mathrm{b}}$ & $896(63.9)$ & $8190(60.3)$ & $84(41.8)$ & $4929(37.8)$ \\
\hline \multicolumn{5}{|l|}{ Alcohol consumption ${ }^{\mathrm{b}}$} \\
\hline$\geq 2$ units/day, $N(\%)$ & $30(2.2)$ & $372(2.8)$ & $7(3.5)$ & $1121(8.7)$ \\
\hline$\geq 3$ units/day, $N(\%)^{\mathrm{a}}$ & 0 & $4(0)$ & 0 & $28(0.2)$ \\
\hline Secondary osteoporosis, $N(\%)^{\mathrm{d}}$ & $706(50.4)$ & $3656(26.9)$ & $128(63.7)$ & $1951(15.0)$ \\
\hline Exposed to glucocorticoids, $N(\%)^{\mathrm{e}}$ & $441(31.5)$ & $1587(11.7)$ & $120(59.7)$ & $1417(10.9)$ \\
\hline Rheumatoid arthritis, $N(\%)^{\mathrm{b}}$ & $188(13.4)$ & $672(4.9)$ & $33(16.4)$ & $375(2.9)$ \\
\hline Premature menopause, $N(\%)^{\mathrm{b}}$ & $259(8.5)$ & $1591(11.7)$ & - & - \\
\hline Hyperthyroidism, $N(\%)^{\mathrm{b}}$ & $57(4.1)$ & $400(2.9)$ & $1(0.5)$ & $127(1.0)$ \\
\hline Diabetes type $1, N(\%)^{\mathrm{b}}$ & $15(1.1)$ & $62(0.5)$ & $4(2.0)$ & $86(0.7)$ \\
\hline
\end{tabular}

${ }^{a}$ Use of bisphosphonates were defined as at least two prescriptions of bisphosphonates were filled during a 6 months period or infusion of zoledronic acid once a year

${ }^{\mathrm{b}}$ Self-reported

${ }^{\mathrm{c}}$ Previous fractures in hip, wrist, or spine after 40 years

${ }^{\mathrm{d}}$ Secondary osteoporosis defined as at least one of the following: exposed to glucocorticoids (min 90 DDD or 3 months treatment), rheumatoid arthritis, menopause or surgical removal of ovaries before 45 years, hyperthyroidism, or diabetes mellitus type 1 . The number of patients with of secondary osteoporosis is less than the sum of the different conditions, as 602 women and 145 men had more than one criterion for secondary osteoporosis

${ }^{\mathrm{e}}$ Used the drug during the follow-up period, data were retrieved from the Norwegian prescription register

numbers for men were 9 and 250 (Table 2). Adjusted only for age, the HR for hip/forearm fracture among women using BPs was 0.90 (95\% CI 0.71-1.14) (Table 2). However, after adjustment for individual FRAX scores, women had a HR for hip/ forearm fractures of 0.67 (95\% CI $0.52-0.86$ ) and 0.68 (0.46-1.02) for hip fractures solely. Only 9 men using BPs experienced fractures, and no difference in the fracture risk was shown between users and non-users (Table 2).

\section{Sensitivity analyses}

In women with secondary osteoporosis, the HR for fractures of the hip/forearm was 0.54 (95\% CI 0.37-0.82), hip fractures 0.54 (95\% CI $0.30-0.99)$, and forearm fractures 0.62 (95\% CI $0.37-$ 1.02) (Table 3a). In women using GCs (Table 3b), the HR was 0.35 (95\% CI 0.19-0.66) for fractures in hip/forearm, 0.33 (95\% CI $0.13-0.90$ ) for hip fractures, and 0.45 (95\% CI 0.21-0.98) for forearm fractures. When examining women with high risk for fracture defined as FRAX $\geq 20(N=3001)$, the HR for fracture in hip/forearm was $0.59(0.44-0.80)$ (data not shown).
There were only minor differences when accounting for potential variation in assumed duration of the antiresorptive effect of BPs after end of supply. When duration of exposure was assumed to last 3 months after end of drug supply, the HR among women (adjusted for age and FRAX $\mathrm{XOF}_{\mathrm{MO}}$ without BMD) was 0.63 (0.49-0.81) When the exposure was assumed to last 9 months, the respective values were $0.68(0.53-0.87)$. In the model censoring BPs users 6 months after stopping BPs treatment, the HR were $0.73(0.58-0.93)$.

In propensity score stratified models, estimated associations between use of bisphosphonates and fractures were very similar to those estimated from the model adjusted for age and FRAX. For women, the HR among users of BPs was 0.75 $(0.58-0.95)$ and men $1.38(0.63-4.05)$.

\section{Discussion}

In this population-based study conducted between 2006 and 2012 , the risk of fracture in the forearm or hip was $33 \%$ lower 
Table 2 Hazard ratios for the association between use of bisphosphonates and fractures in the 3 different models

\begin{tabular}{|c|c|c|c|c|c|c|}
\hline & $N$ & Fractures & $\begin{array}{l}\text { Fractures } / 1000 \\
\text { individuals }\end{array}$ & $\begin{array}{l}\text { Model 1, } \\
\text { adjusted for age }\end{array}$ & $\begin{array}{l}\text { Model 2, } \\
\text { adjusted for FRAX }\end{array}$ & $\begin{array}{l}\text { Model 3, adjusted } \\
\text { for age and FRAX }\end{array}$ \\
\hline \multicolumn{7}{|l|}{ Hip and forearm fractures } \\
\hline \multicolumn{7}{|l|}{ Women } \\
\hline Bisphosphonates no & 13,588 & 828 & $60.9(57.0-65.1)$ & Reference & Reference & Reference \\
\hline Bisphosphonates yes & 1402 & 94 & $67.0(54.8-81.7)$ & $0.90(0.71-1.14)$ & $0.64(0.50-0.82)$ & $0.67(0.52-0.86)$ \\
\hline \multicolumn{7}{|l|}{ Men } \\
\hline Bisphosphonates no & 13,038 & 251 & $19.2(16.9-21.7)$ & Reference & Reference & Reference \\
\hline Bisphosphonates yes & 201 & 9 & $44.7(22.0-86.0)$ & $2.00(0.94-4.25)$ & $0.80(0.34-1.88)$ & $1.13(0.50-2.58)$ \\
\hline \multicolumn{7}{|l|}{ Hip fractures } \\
\hline \multicolumn{7}{|l|}{ Women } \\
\hline Bisphosphonates no & 13,588 & 230 & $16.9(14.9-19.3)$ & Reference & Reference & Reference \\
\hline Bisphosphonates yes & 1402 & 35 & $25.0(17.7-34.9)$ & $0.87(0.59-1.27)$ & $0.64(0.42-0.98)$ & $0.68(0.46-1.02)$ \\
\hline \multicolumn{7}{|l|}{ Men } \\
\hline Bisphosphonates no & 13,038 & 128 & $9.8(8.2-11.7)$ & Reference & Reference & Reference \\
\hline Bisphosphonates yes & 201 & 5 & $24.9(9.2-60.3)$ & $1.33(0.42-4.20)$ & $0.31(0.09-1.17)$ & $0.78(0.22-2.68)$ \\
\hline \multicolumn{7}{|l|}{ Forearm fractures } \\
\hline \multicolumn{7}{|l|}{ Women } \\
\hline Bisphosphonates no & 13,588 & 601 & $44.2(40.9-47.8)$ & Reference & Reference & Reference \\
\hline Bisphosphonates yes & 1402 & 61 & $43.5(33.7-55.9)$ & $0.96(0.72-1.29)$ & $0.87(0.64-1.18)$ & $0.87(0.64-1.18)$ \\
\hline \multicolumn{7}{|l|}{ Men } \\
\hline Bisphosphonates no & 13,038 & 123 & $9.4(7.8-11.3)$ & Reference & Reference & Reference \\
\hline Bisphosphonates yes & 201 & 4 & $19.9(6.4-53.5)$ & $3.14(1.15-8.55)$ & $2.33(0.80-6.81)$ & $2.21(0.73-6.63)$ \\
\hline
\end{tabular}

Table 3 Sensitivity analyses including (a) women with all types of secondary osteoporosis and (b) women and men using glucocorticoids

\begin{tabular}{|c|c|c|c|c|c|}
\hline & $N$ & Fractures & $\begin{array}{l}\text { Fractures/1000 } \\
\text { individuals }\end{array}$ & $\begin{array}{l}\text { Model 1, } \\
\text { adjusted for age }\end{array}$ & $\begin{array}{l}\text { Model 2, adjusted } \\
\text { for age and FRAX }\end{array}$ \\
\hline \multicolumn{6}{|c|}{ a. Women with all types of secondary osteoporosis } \\
\hline \multicolumn{6}{|c|}{ Hip and forearm fractures } \\
\hline Bisphosphonates no & 3656 & 211 & $57.7(50.5-65.9)$ & Reference & Reference \\
\hline Bisphosphonates yes & 706 & 40 & $56.7(41.3-77.0)$ & $0.75(0.51-1.10)$ & $0.54(0.37-0.82)$ \\
\hline \multicolumn{6}{|l|}{ Hip fractures } \\
\hline Bisphosphonates no & 3656 & 73 & $20.0(15.7-25.2)$ & Reference & Reference \\
\hline Bisphosphonates yes & 706 & 17 & $24.1(14.5-39.1)$ & $0.75(0.42-1.34)$ & $0.54(0.30-0.99)$ \\
\hline \multicolumn{6}{|l|}{ Forearm fractures } \\
\hline Bisphosphonates no & 3656 & 139 & $38.0(32.1-44.9)$ & Reference & Reference \\
\hline Bisphosphonates yes & 706 & 25 & $35.4(23.5-52.6)$ & $0.81(0.50-1.32)$ & $0.62(0.37-1.02)$ \\
\hline \multicolumn{6}{|c|}{ b. Women exposed to glucocorticoids } \\
\hline \multicolumn{6}{|l|}{ Hip and forearm fractures } \\
\hline Bisphosphonates no & 1587 & 81 & $51.0(41.0-63.3)$ & Reference & Reference \\
\hline Bisphosphonates yes & 441 & 17 & $38.5(23.3-62.2)$ & $0.48(0.26-0.88)$ & $0.35(0.19-0.66)$ \\
\hline \multicolumn{6}{|l|}{ Hip fractures, } \\
\hline Bisphosphonates no & 1587 & 33 & $20.8(14.6--29.4)$ & Reference & Reference \\
\hline Bisphosphonates yes & 441 & 6 & $13.6(5.5-30.9)$ & $0.64(0.42-0.98)$ & $0.33(0.13-0.90)$ \\
\hline \multicolumn{6}{|c|}{ Forearm fractures, women } \\
\hline Bisphosphonates no & 1587 & 48 & $30.2(22.6-40.2)$ & Reference & Reference \\
\hline Bisphosphonates yes & 441 & 12 & $27.2(14.8-48.4)$ & $0.57(0.27-1.21)$ & $0.45(0.21-0.98)$ \\
\hline
\end{tabular}


in women using BPs when taking into account individual fracture risk assessment (FRAX®) scores. This is in agreement with results from RCTs, and the fact that different sensitivity analyses broadly gave the same results seems reassuring. The association was most pronounced for hip fractures. A risk reduction could not be shown for men, probably due to lack of power as only 201 men were BP users with only nine fractures occurring among these during follow-up. Notably, $98 \%$ and $99 \%$ of women and men, respectively, were treated with oral BPs, preferentially alendronate. About $50 \%$ of the women using BPs had secondary osteoporosis and a third of these had GIOP. Interestingly, women with secondary osteoporosis seemed to benefit the most, exhibiting a relative risk reduction of $46 \%$, and those with GIOP a reduction by $65 \%$.

It is important to complement RCTs with observational studies addressing the effect of BPs in daily clinical practice. The clinical picture differs between those participating in RCTs and patients in real life, the latter exhibiting comorbidity and more severe osteoporosis [9]. The drug adherence also seems to be poorer in clinical practice. Accordingly, the anti-fracture efficacy seen in RCTs does not necessarily translate to real life.

A crude comparison of the fracture rates demonstrates that BP users had a higher fracture rate than non-users. This mirrors the appropriate targeting of BPs to individuals at substantially elevated fracture risk, with BP users being older, three times as likely to have sustained prior fractures and more likely to suffer from secondary osteoporosis. Hence, in the present study, women prescribed BPs had a risk for a major osteoporotic fracture of $26 \%$ according to FRAX (without measured BMD), a base risk more than twice that of untreated women in the study. When effects are adjusted for this difference, it becomes evident that the observed fracture rates represent a substantial reduction of risk in those who received BP treatment.

The estimated reduction of fracture risk was somewhat lower than in the initial RCTs of oral BPs. The results are not necessarily comparable, due to strict inclusion and exclusion criteria in RCTs and potential residual confounding in our observational study. In the pivotal fracture intervention trial (FIT) of alendronate including women with existing vertebral fractures, fractures at the hip and wrist were reduced by 51 and $48 \%$, respectively [28]. In the subgroups of women with a very high risk for fracture defined as FRAX $\geq 20$, the risk reduction was estimated to $41 \%$. This emphasizes the importance of treating women at high risk. Women with high FRAX often have comorbidities that exclude them from participation in RCTs [29]. Our results are comparable to those found in studies from Denmark and Sweden [14, 30].

In total, among those treated with BPs, $50 \%$ of women and $63 \%$ of men had secondary osteoporosis, where GIOP accounted for $31 \%$ and $59 \%$, respectively. Given potential differences in the effect of BPs on fracture reduction in primary and secondary osteoporosis, a subanalysis of these groups was performed. Among women with secondary osteoporosis, the fracture reduction in our study was $46 \%$, and among users of GCs as high as $65 \%$. There is limited evidence for an anti-fracture effect of BPs for most types of secondary osteoporosis, except for GIOP and osteoporosis induced by hypogonadism in men. Notably, most studies were not powered to assess fracture risk reduction. In an RCT addressing GIOP, a trend towards risk reduction of vertebral fractures was observed after 1 year of alendronate treatment. In the open-label extension study at 2 years, the risk of vertebral fracture was reduced by $90 \%$. The study did not have sufficient power to demonstrate an effect on non-vertebral fractures [31, 32].

The reason for the more pronounced fracture reduction among GCs users may be attributed to the severity of their osteoporosis. GCs exert a multitude of adverse effects on bone and muscle contributing to a high risk for fractures. Due to impairment of bone quality, these patients experience fractures at a higher BMD than non-users. GCs compromise inhibition of bone formation with a concomitant stimulation of bone resorption including increased apoptosis of mature osteoblasts and osteocytes; impaired differentiation of osteoblasts; and an increased lifespan of osteoclasts [33]. GCs further inhibit the intestinal calcium absorption. In addition, the diseases treated by GCs may also increase fracture risk themselves through inflammatory mediators, inappropriate diet, and inactivity [33-35].

Oral BPs, and preferentially alendronate, are the recommended initial treatment for osteoporosis worldwide due to their efficacy, beneficial safety profile, and low cost. In line with this, alendronate was used by the majority of the study subjects, whereas only 69 individuals (4\% of the BP users) were treated with iv zoledronic acid. Zoledronic acid is mainly given in a hospital setting in Norway - and thus, not registered in NorPD. Hence, the frequency of use of this drug is probably underestimated. It should be recalled that the number of patients treated with zoledronic acid was much lower at the time the study was conducted than today. Moreover, zoledronic acid is also used in the treatment of hypercalcemia and as adjuvant treatment to patients with cancer. Other treatment options than BPs were used by very few.

Regarding adherence among the included participants with at least two filled prescriptions, $80 \%$ of the women and $77 \%$ of the men had an MPR $\geq 80$ during follow-up. However, $15 \%$ of the women and $26 \%$ of the men filled only one prescription or used oral BP for less than 6 months (counted as unexposed in this study), illustrating that there is still a problem regarding adherence. Nevertheless, the adherence observed in our study is satisfactory compared to most studies on oral BPs [26]. 
We may assume that the compliance and adherence is better in RCTs with close follow-up than in the general patient population. Moreover, the route of administration will impact the adherence. Most probably the adherence is better for zoledronic acid that is given intravenously once yearly, and for denosumab administered subcutaneously every 6 months than for alendronate orally once a week.

The strength of our study is the population-based design and the large registers. The HUNT study also includes substantial information regarding risk for fractures, which reduces residual confounding. An additional strength is that we had access to calculated FRAX scores based on data collected in the HUNT study and the NorPD in all participants, although without BMD. Further, we have used time-dependent drug exposure to evaluate the effect of BPs during the follow-up period, thus avoiding immortal time bias, which refers to a period of follow-up during which, by design, death, or the study outcome cannot occur [36].

An important limitation of any observational study is that there may be unmeasured confounders which may lead to biased estimates [7]. In our study, there are obvious differences between individuals exposed and not exposed to BPs, and such potential confounders are not necessarily captured by age and FRAX. However, the fact that estimates from a sensitivity analysis using a stratified propensity score model based on a large number of potential confounders led to broadly similar results is reassuring. Furthermore, our results are comparable to a review including RCTs addressing the effect of BPs on non-vertebral fractures. In a total of five RCTs including 30.000 postmenopausal women, the HR for any non-vertebral fracture was $0.76(0.70-0.81)$ among users of BPs [37].

Not all types of fractures could be included in the study as the fracture register only includes fractures of the hip and forearm. Further, calcium supplements with or without vitamin $\mathrm{D}$ were not included in the analyses as they are available without prescription in Norway. Among men, there were both few users of BPs as well as few fractures, with a resulting low statistical power. As noted above, the use of zoledronic acid may be underestimated since drugs given in hospital are not included in the NorPD. However, any uncaptured zoledronic acid use in the nominally untreated population would only conservatively bias the treatment effect we report here. As in all pharmacoepidemiological studies based on filled prescriptions, there is the possibility that individuals may accumulate old drugs. In general, in such studies there is no way to ensure that individuals actually use medication as prescribed. At last we only have information regarding prescription of BPs from 2004 (when NorPD was established) and cannot distinguish between treatment naïve and historical users.
The conclusion of this population-based study is that women treated with BPs displayed a reduced risk of fractures at the hip and forearm comparable to results from RCTs. The relative risk reduction was higher among women with secondary osteoporosis compared to primary osteoporosis. The most pronounced relative risk reduction was seen in women with glucocorticoidinduced osteoporosis.

Supplementary Information The online version contains supplementary material available at https://doi.org/10.1007/s00198-021-05845-2.

Acknowledgments The Nord-Trøndelag Health Study (The HUNT Study) is a collaboration between HUNT Research Center (Faculty of Medicine and Health Sciences, Norwegian University of Science and Technology (NTNU)), Trøndelag County Council, Central Norway Regional Health Authority, and the Norwegian Institute of Public Health.

Conflicts of interest Mari Hoff declares that she has no conflict of interest. Bo Abrahamsen has institutional research contracts with UCB, Novartis and Kyowa-Kirin with funds paid to the institution. Personal speaker or consulting fees from UCB, Amgen, Eli Lilly, and Pharmacosmos. Unni Syversen has received research grants from or served as a Principal Investigator in studies conducted by Amgen, Eli Lilly, Novartis, Merck, and Wyeth pharmaceuticals. Eva Skovlund, Haakon E. Meyer, Arnulf Langhammer, Anne Johanne Søgaard, Kristin Holvik, and Berit Schei declare that they have no conflict of interest.

Funding Open Access funding provided by NTNU Norwegian University of Science and Technology (incl St. Olavs Hospital Trondheim University Hospital). Mari Hoff received a post-doctoral fellowship grant from the Liaison Committee between the Central Norway Regional Health Authority (RHA) and the Norwegian University of Science and Technology (NTNU).

Open Access This article is licensed under a Creative Commons Attribution-NonCommercial 4.0 International License, which permits any non-commercial use, sharing, adaptation, distribution and reproduction in any medium or format, as long as you give appropriate credit to the original author(s) and the source, provide a link to the Creative Commons licence, and indicate if changes were made. The images or other third party material in this article are included in the article's Creative Commons licence, unless indicated otherwise in a credit line to the material. If material is not included in the article's Creative Commons licence and your intended use is not permitted by statutory regulation or exceeds the permitted use, you will need to obtain permission directly from the copyright holder. To view a copy of this licence, visit http:// creativecommons.org/licenses/by-nc/4.0/.

\section{References}

1. (1993) Consensus development conference: Diagnosis, prophylaxis, and treatment of osteoporosis. Am J Med 94(6):646-650. https:// doi.org/10.1016/0002-9343(93)90218-e

2. Black DM, Rosen CJ (2016) Clinical practice. Postmenopausal osteoporosis. N Engl J Med 374(3):254-262. https://doi.org/10. 1056/NEJMcp1513724

3. Compston JE, McClung MR, Leslie WD (2019) Osteoporosis. Lancet 393(10169):364-376. https://doi.org/10.1016/S01406736(18)32112-3 
4. Crandall CJ, Newberry SJ, Diamant A, Lim YW, Gellad WF, Suttorp MJ, Motala A, Ewing B, Roth B, Shanman R, Timmer M, Shekelle PG (2012) Treatment to prevent fractures in men and women with low bone density or osteoporosis: update of a 2007 report. Rockville MD

5. Crandall CJ, Newberry SJ, Diamant A, Lim YW, Gellad WF, Booth MJ, Motala A, Shekelle PG (2014) Comparative effectiveness of pharmacologic treatments to prevent fractures: an updated systematic review. Ann Intern Med 161(10):711-723. https://doi. org/10.7326/M14-0317

6. Wells GA, Cranney A, Peterson J, Boucher M, Shea B, Robinson V, Coyle D, Tugwell P (2008) Alendronate for the primary and secondary prevention of osteoporotic fractures in postmenopausal women. Cochrane Database Syst Rev 1:CD001155. https://doi.org/ 10.1002/14651858.CD001155.pub2

7. Strom O, Lauppe R, Ljunggren O, Spangeus A, Ortsater G, O'Kelly J, Akesson K (2020) Real-world effectiveness of osteoporosis treatment in the oldest old. Osteoporos Int 31(8):1525-1533. https://doi. org/10.1007/s00198-020-05380-6

8. Yusuf AA, Cummings SR, Watts NB, Feudjo MT, Sprafka JM, Zhou J, Guo H, Balasubramanian A, Cooper C (2018) Real-world effectiveness of osteoporosis therapies for fracture reduction in post-menopausal women. Arch Osteoporos 13(1):33. https://doi. org/10.1007/s11657-018-0439-3

9. Reyes C, Pottegard A, Schwarz P, Javaid MK, Van Staa TP, Cooper C, Diez-Perez A, Abrahamsen B, Prieto-Alhambra D (2016) Real-life and RCT participants: alendronate users versus FITs' trial eligibility criterion. Calcif Tissue Int 99(3):243-249. https://doi.org/10.1007/s00223-016-0141-7

10. Wang YK, Zhang YM, Qin SQ, Wang X, Ma T, Guo JB, Zhu C, Luo ZJ (2018) Effects of alendronate for treatment of glucocorticoid-induced osteoporosis: a meta-analysis of randomized controlled trials. Medicine (Baltimore) 97(42):e12691. https://doi.org/10.1097/MD.0000000000012691

11. Allen CS, Yeung JH, Vandermeer B, Homik J (2016) Bisphosphonates for steroid-induced osteoporosis. Cochrane Database System Rev 10(10):Cd001347. https://doi.org/10.1002/ 14651858.CD001347.pub2

12. Olsen KR, Hansen C, Abrahamsen B (2013) Association between refill compliance to oral bisphosphonate treatment, incident fractures, and health care costs-an analysis using national health databases. Osteoporos Int 24(10):2639-2647. https://doi.org/10.1007/ s00198-013-2365-y

13. Abrahamsen B, Eiken P, Prieto-Alhambra D, Eastell R (2016) Risk of hip, subtrochanteric, and femoral shaft fractures among mid and long term users of alendronate: nationwide cohort and nested casecontrol study. BMJ 353:i3365. https://doi.org/10.1136/bmj.i3365

14. Nordstrom P, Toots A, Gustafson Y, Thorngren KG, Hommel A, Nordstrom A (2017) Bisphosphonate use after hip fracture in older adults: a Nationwide retrospective cohort study. J Am Med Dir Assoc 18(6):515-521. https://doi.org/10.1016/j.jamda.2016.12.083

15. Hoff M, Skurtveit S, Meyer HE, Langhammer A, Sogaard AJ, Syversen U, Abrahamsen B, Schei B (2015) Use of antiosteoporotic drugs in Central Norway after a forearm fracture. Arch Osteoporos 10:235. https://doi.org/10.1007/s11657-0150235-2

16. Hoff M, Skurtveit S, Meyer HE, Langhammer A, Sogaard AJ, Syversen U, Skovlund E, Abrahamsen B, Forsmo S, Schei B (2018) Anti-osteoporosis drug use: too little, too much, or just right? The HUNT study, Norway. Osteoporos Int 29(8):18751885. https://doi.org/10.1007/s00198-018-4560-3

17. Devold HM, Doung GM, Tverdal A, Furu K, Meyer HE, Falch JA, Sogaard AJ (2010) Prescription of anti-osteoporosis drugs during 2004-2007-a nationwide register study in Norway. Eur J Clin Pharmacol 66(3):299-306. https://doi.org/10.1007/s00228-0090746-0
18. Hernlund E, Svedbom A, Ivergard M, Compston J, Cooper C, Stenmark J, McCloskey EV, Jonsson B, Kanis JA (2013) Osteoporosis in the European Union: medical management, epidemiology and economic burden. A report prepared in collaboration with the International Osteoporosis Foundation (IOF) and the European Federation of Pharmaceutical Industry Associations (EFPIA). Arch Osteoporos 8:136. https://doi.org/10.1007/s11657013-0136-1

19. Krokstad S, Langhammer A, Hveem K, Holmen TL, Midthjell K, Stene TR, Bratberg G, Heggland J, Holmen J (2013) Cohort profile: the HUNT study, Norway. Int J Epidemiol 42(4):968-977. https:// doi.org/10.1093/ije/dys095

20. Blum MR, Bauer DC, Collet TH, Fink HA, Cappola AR, da Costa BR, Wirth CD, Peeters RP, Asvold BO, den Elzen WP, Luben RN, Imaizumi M, Bremner AP, Gogakos A, Eastell R, Kearney PM, Strotmeyer ES, Wallace ER, Hoff M, Ceresini G, Rivadeneira F, Uitterlinden AG, Stott DJ, Westendorp RG, Khaw KT, Langhammer A, Ferrucci L, Gussekloo J, Williams GR, Walsh JP, Juni P, Aujesky D, Rodondi N, Thyroid Studies C (2015) Subclinical thyroid dysfunction and fracture risk: a meta-analysis. JAMA 313(20):2055-2065. https://doi.org/10.1001/jama.2015. 5161

21. Hoff M, Skovlund E, Skurtveit S, Meyer HE, Langhammer A, Sogaard AJ, Syversen U, Forsmo S, Abrahamsen B, Schei B (2020) Proton pump inhibitors and fracture risk. The HUNT study, Norway. Osteoporosis Int 31(1):109-118. https://doi.org/10.1007/ s00198-019-05206-0

22. Furu K (2008) Establishment of the nationwide Norwegian Prescription Database (NorPD) - new opportunities for research in pharmacoepidemiology in Norway. Norsk Epidemiol 129-136

23. Kanis JA, Oden A, Johansson H, Borgstrom F, Strom O, McCloskey E (2009) FRAX and its applications to clinical practice. Bone 44(5):734-743. https://doi.org/10.1016/j.bone.2009.01.373

24. Hoff M, Meyer HE, Skurtveit S, Langhammer A, Sogaard AJ, Syversen U, Dhainaut A, Skovlund E, Abrahamsen B, Schei B (2017) Validation of FRAX and the impact of self-reported falls among elderly in a general population: the HUNT study, Norway. Osteoporos Int 28(10):2935-2944. https://doi.org/10.1007/s00198017-4134-9

25. Vollset SE (1993) Confidence intervals for a binomial proportion. Stat Med 12(9):809-824. https://doi.org/10.1002/sim.4780120902

26. Devold HM, Furu K, Skurtveit S, Tverdal A, Falch JA, Sogaard AJ (2012) Influence of socioeconomic factors on the adherence of alendronate treatment in incident users in Norway. Pharmacoepidemiol Drug Saf 21(3):297-304. https://doi.org/10. $1002 /$ pds. 2344

27. Iglay K, Cao X, Mavros P, Joshi K, Yu S, Tunceli K (2015) Systematic literature review and meta-analysis of medication adherence with once-weekly versus once-daily therapy. Clin Ther 37(8):1813-1821.e1811. https://doi.org/10.1016/j.clinthera.2015. 05.505

28. Black DM, Cummings SR, Karpf DB, Cauley JA, Thompson DE, Nevitt MC, Bauer DC, Genant HK, Haskell WL, Marcus R, Ott SM, Torner JC, Quandt SA, Reiss TF, Ensrud KE (1996) Randomised trial of effect of alendronate on risk of fracture in women with existing vertebral fractures. Fracture Intervention Trial Research Group. Lancet 348(9041):1535-1541. https://doi. org/10.1016/s0140-6736(96)07088-2

29. van de Glind EM, Willems HC, Eslami S, Abu-Hanna A, Lems WF, Hooft L, de Rooij SE, Black DM, van Munster BC (2016) Estimating the time to benefit for preventive drugs with the statistical process control method: an example with alendronate. Drugs Aging 33(5):347-353. https://doi.org/10.1007/s40266-016-0344-7

30. Abrahamsen B (2017) The emperor redressed: treating osteoporosis to prevent hip fractures in the oldest old. J Intern Med 282(6):560 562. https://doi.org/10.1111/joim. 12700 
31. Saag KG, Emkey R, Schnitzer TJ, Brown JP, Hawkins F, Goemaere S, Thamsborg G, Liberman UA, Delmas PD, Malice MP, Czachur M, Daifotis AG (1998) Alendronate for the prevention and treatment of glucocorticoid-induced osteoporosis. Glucocorticoid-Induced Osteoporosis Intervention Study Group. N Engl J Med 339(5):292-299. https://doi.org/10.1056/ NEJM199807303390502

32. Adami G, Saag KG (2019) Glucocorticoid-induced osteoporosis: 2019 concise clinical review. Osteoporos Int 30(6):1145-1156. https://doi.org/10.1007/s00198-019-04906-x

33. Raterman HG, Bultink IEM, Lems WF (2019) Current treatments and new developments in the management of glucocorticoidinduced osteoporosis. Drugs 79(10):1065-1087. https://doi.org/ 10.1007/s40265-019-01145-6

34. Bultink IE, Vis M, van der Horst-Bruinsma IE, Lems WF (2012) Inflammatory rheumatic disorders and bone. Curr Rheumatol Rep 14(3):224-230. https://doi.org/10.1007/s11926-012-0252-8
35. Bultink IE, Baden M, Lems WF (2013) Glucocorticoid-induced osteoporosis: an update on current pharmacotherapy and future directions. Expert Opin Pharmacother 14(2):185-197. https://doi.org/ 10.1517/14656566.2013.761975

36. Levesque LE, Hanley JA, Kezouh A, Suissa S (2010) Problem of immortal time bias in cohort studies: example using statins for preventing progression of diabetes. BMJ 340:b5087. https://doi. org/10.1136/bmj.b5087

37. Mackey DC, Black DM, Bauer DC, McCloskey EV, Eastell R, Mesenbrink P, Thompson JR, Cummings SR (2011) Effects of antiresorptive treatment on nonvertebral fracture outcomes. J Bone Miner Res 26(10):2411-2418. https://doi.org/10.1002/jbmr. 446

Publisher's note Springer Nature remains neutral with regard to jurisdictional claims in published maps and institutional affiliations. 